\title{
THE INFLUENCE OF OXIME SELECTION ON THE EFFICACY OF ANTIDOTAL TREATMENT OF SOMAN-POISONED RATS
}

\begin{abstract}
Jiři Kassa, Josef Fusek
Purkyně Military Medical Academy, Hradec Králové: Department of Toxicology

Summary: 1. The influence of some acetylcholinesterase reactivators (HI-6, obidoxime, pralidoxime) on the efficacy of antidotal treatment to eliminate soman-induced disturbance of respiration and circulation and to protect experimental animals poisoned with supralethal dose of soman $\left(1.5 \times \mathrm{LD}_{50}\right)$ was investigated in a rat model with on-line monitoring of respiratory and circulatory parameters. 2. Obidoxime or pralidoxime in combination with atropine were insufficient to enable soman-poisoned rats to survive for 2 hours when given 1 minute after the administration of soman. 3 . On the other hand, the ability of the oxime HI-6 in combination with atropine to prevent soman-induced alteration of respiration and circulation was significantly higher. Some rats treated with HI-6 in combination with atropine were fully protected against the lethal toxic effects of soman within 2 hours following soman administration. 4. Our findings confirm that the oxime HI-6 seems to be a much more suitable and efficacious acetylcholinesterase reactivator for the antidotal treatment of severe acute soman-induced poisoning than currently used obidoxime or pralidoxime.
\end{abstract}

Key words: Soman; Atropine; HI-6; Obidoxime; Pralidoxime; Rat

\section{Introduction}

Soman (O-pinacolyl methylphosphonofluoridate), a highly toxic organophosphorus (OP) compound, belongs to the class of chemical warfare agents, called nerve agents, that represent potential threats to both military and civilian populations, as evidenced in terroristic attacks in Tokyo and Matsumoto (19). They exert their toxic effects by the phosphonylation and subsequent inactivation of acetylcholinesterase (AChE, EC 3.1.1.7). The inactivation of AChE allows the accumulation of acetylcholine ( $\mathrm{ACh})$ in the cholinergic clefts of the central and peripheral nervous systems. Subsequent widespread overstimulation of cholinergic receptors is manifested as salivation, lacrimation, sweating, diarrhea, urination, muscular twitching and fibrilation and ultimately tonic/clonic convulsions $(17,25)$. In addition, nerve agentinduced centrally mediated seizures can rapidly progress to status epilepticus and contribute to profound brain damage and cardiac pathology $(15,18,26)$.

The currently recommended treatment against OP intoxication consists of the combined administration of anticholinergic drugs (preferably atropine) and oximes (preferably pralidoxime and obidoxime). Atropine is a basic component of this antidotal therapy because it antagonizes $\mathrm{ACh}$ action at muscarinic sites, alleviating tracheobronchial and salivary secretion, bronchoconstriction, miosis, intestinal mobility and bradycardia. The oximes can reactivate the phosphonylated $\mathrm{AChE}$ if administered prior to its irreversible inactivation, referred to as "aging" (6). Unfortunately, soman has been found to be resistant to this standard antidotal treatment, because of the rapid aging of soman-phosphonylated $\mathrm{AChE}$ and the existence of a soman depot in the poisoned organisms $(2,8,9)$. Thus, the replacement of pralidoxime or obidoxime with a more effective oxime has been a long-standing goal for the treatment of severe acute soman poisoning.

In the 1970s, a series of bispyridinium oximes, designated $\mathrm{H}$ oximes, was synthesized (20). Among $\mathrm{H}$ oximes, HI-6 has been the best studied, because it is currently regarded as the more promising oxime against nerve agent poisoning compared to the currently used oximes $(20,23)$. Some studies demonstrated that the ability of HI-6 to antagonize soman-induced toxic effects is significantly higher compared to obidoxime or pralidoxime $(4,10,12,24)$. The relatively high therapeutic potency of the oxime HI-6 may be due to various antidotal mechanisms based on reactivation of phosphonylated $\mathrm{AChE}$, direct antimuscarinic and ganglion blocking actions, restoration of neuromuscular transmission, retardation of the formation of the aged inhibitor-enzyme complex and inhibition of acetylcholine release $(10,12,20,27)$. The question remains as to whether the higher efficiency of HI-6 to reactivate soman-inhibited AChE corresponds to its greater ability to prevent soman-exposed animals from exhibiting disturbance of vital functions associated with such poisoning, thus enabling rats poisoned with an otherwise supralethal dose of soman to survive. 
The purpose of this study was to compare the influence of oximes studied (obidoxime, pralidoxime, HI-6) on the elimination of soman-induced disturbance of respiration and circulation as well as on the survival of rats poisoned with a supralethal dose of soman.

\section{Methods}

Male albino Wistar rats weighing 180-200 g were purchased from VÚFB Konárovice (Czech Republic). They were kept in an air-conditioned room with light from 07.00h to $19.00 \mathrm{~h}$ and allowed free access to standard food and tap water. Handling of experimental animals was done under the supervision of the Ethics Committee of the Purkyně Military Medical Academy and the Medical Faculty of Charles University in Hradec Králové (Czech Republic).

Soman was purchased from Zemianské Kostolany (Slovak Republic) and was $98.5 \%$ pure. The oxime HI-6 of $99.0 \%$ purity was synthesized at the Department of Toxicology of the Purkyně Military Medical Academy in Hradec Králové (Czech Republic). All other chemicals and drugs of analytical grade were obtained commercially and used without further purification.

The rats were divided into groups of six animals, anaesthesized (urethane i.p., $1 \mathrm{~g} / \mathrm{kg}$ b.w.) and heparinized to prevent coagulation (heparin, i.v., $25 \mathrm{mg} / \mathrm{kg}$ b.w.). After the onset of anaesthesia, the animals were positioned on a heatable operating table (Zimmermann, Leipzig, Germany). The trachea and left carotid artery were prepared after incision of the throat and a tracheal cannula was inserted and connected to a pneumotachygraph with the help of a Fleish tube (Hugo Sachs, Electronics, Freiburg, Germany). The carotid artery was cannulated with teflon catheters and connected to a pressure transducer (Tesla LMP 102, Valašské Meziříčí, Czech Republic). Respiratory rate, minute respiratory volume, heart rate and mean arterial pressure were recorded online by a multi-pen recorder (Rikadenski, Electronics, Freiburg, Germany). Electrocardiograms (ECGs) were recorded using subcutaneous needles and an EKG NEK 401 Instrument (VEB Messerätewerk, Zwönitz, Germany).

After a stabilization period of 15-30 min, baseline values were recorded and the rats were intramuscularly (i.m.) poisoned with soman at a supralethal dose $(90 \mu \mathrm{g} / \mathrm{kg}$, $\left.1.5 \times \mathrm{LD}_{50}\right)$. One minute following soman administration, they were i.m. treated with atropine $(21 \mathrm{mg} / \mathrm{kg})$ alone or with atropine in combination with one of the oximes studied (HI-6, obidoxime, pralidoxime) at equimolar doses (100 $\mu \mathrm{mol} / \mathrm{kg}$ ). The experiments were terminated $120 \mathrm{~min}$ after soman poisoning or by death of animals. The respiratory and circulatory data were recorded to this point. At the end of the experiments, the rats were killed by air embolism into the carotid artery. The experimental data were compared to the data obtained from non-treated soman-poisoned rats.

Mean survival time data are expressed as means \pm SE. Statistical significance was determined by the use of the Wilcoxon, Mann and Whitney U-test and the differences were considered significant when $P<0.05$ (22).

\section{Results}

The absolute baseline values were between $117.2 \pm 8.7$ and $130.8 \pm 9.7 \mathrm{~min}^{-1}$ (respiratory rate), $252.6 \pm 18.0$ and $280.0 \pm 18.2 \mathrm{ml} \mathrm{min}^{-1}$ (minute respiratory volume), $384.0 \pm$ 11.2 and $408.0 \pm 17.3 \mathrm{~min}^{-1}$ (heart rate) and $103.0 \pm 8.3$ and $119.0 \pm 10.2 \mathrm{mmHg}$ (mean arterial pressure). There were no significant differences among the groups at baseline.

All soman-poisoned rats suffered from a rapid respiratory depression if they were not treated. A dramatic decreases in respiratory rate and respiratory volume were recorded immediately after soman challenge. Soman at this supralethal dose also caused a progressive bradycardia followed by hypotension in a few minutes (Fig. 1). The rats died within $6.8 \mathrm{~min}$ on average (Tab. 1).

The treatment of soman-poisoned rats with atropine alone did not prevent soman-induced respiratory depression, changes in mean arterial pressure and ECG changes (Fig. 2). The rats died within $12.5 \mathrm{~min}$ on average (Tab. 1).

The treatment of soman-poisoned rats with pralidoxime or obidoxime in combination with atropine prevented soman-induced respiratory depression, nevertherless, the beneficial effects of these antidotal combinations on mean arterial pressure and ECG were very short-lived and insufficient to prevent death (Figs. 3 and 4). The rats died within 12-24 min on average (Tab. 1).

The treatment of soman-poisoned rats with HI-6 in combination with atropine was able to prevent sufficiently soman-induced respiratory depression too. The beneficial

Tab. 1: Effect of oxime selection on survival time and 120 min survival rate in rats poisoned by soman.

\begin{tabular}{|l|c|c|c|c|c|}
\hline Group & Soman & $\begin{array}{c}\text { Soman } \\
\text { Atropine }\end{array}$ & $\begin{array}{c}\text { Soman } \\
\text { Pralidoxime } \\
+ \text { atropine }\end{array}$ & $\begin{array}{c}\text { Soman } \\
\text { Obidoxime } \\
+ \text { atropine }\end{array}$ & $\begin{array}{c}\text { Soman } \\
\text { HI-6 } \\
+ \text { atropine }\end{array}$ \\
\hline Mean survival time (min, means \pm SE) & $6.8 \pm 1.9$ & $12.5 \pm 3.5$ & $11.6 \pm 3.4$ & $23.4 \pm 8.2^{*}$ & $112.0 \pm 9.6^{* x}$ \\
\hline 120 min survival rate (survivor/total) & $0 / 6$ & $0 / 6$ & $0 / 6$ & $0 / 6$ & $4 / 6$ \\
\hline
\end{tabular}

Statistical significance between non-treated and treated soman poisoning: * $\mathrm{P}<0.05$, between atropine - treated and antidotal mixture - treated soman poisoning: ${ }^{\mathrm{x}} \mathrm{P}<0.05$. 
II

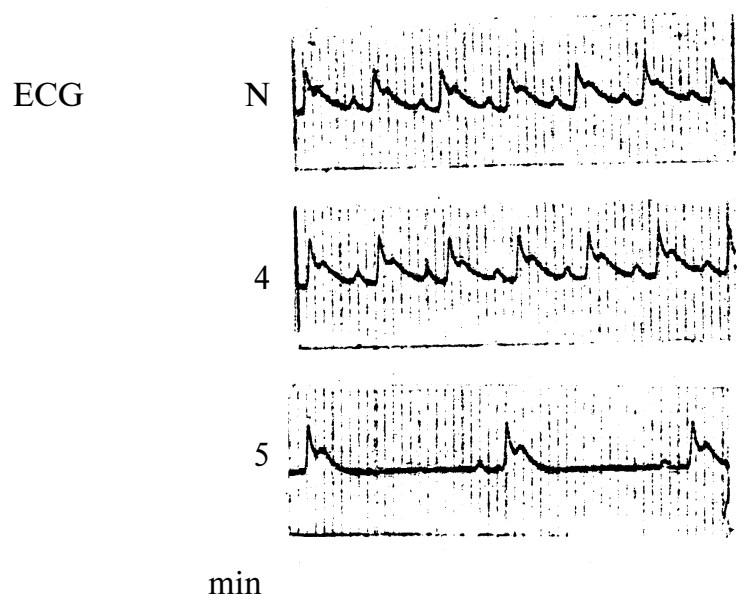

III
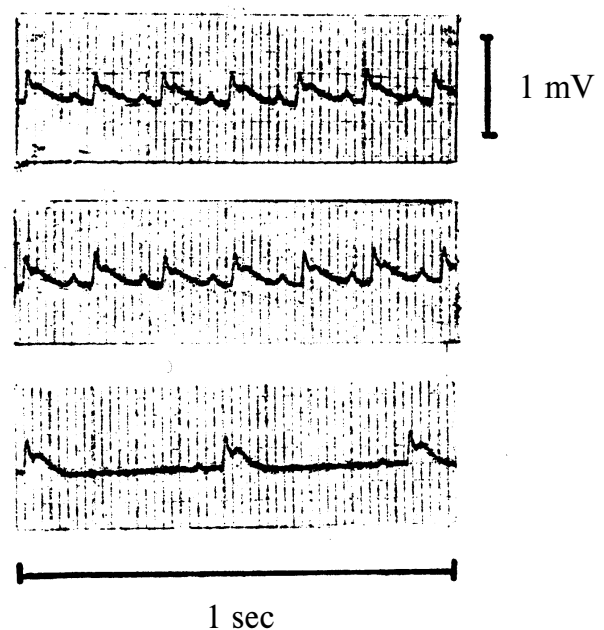

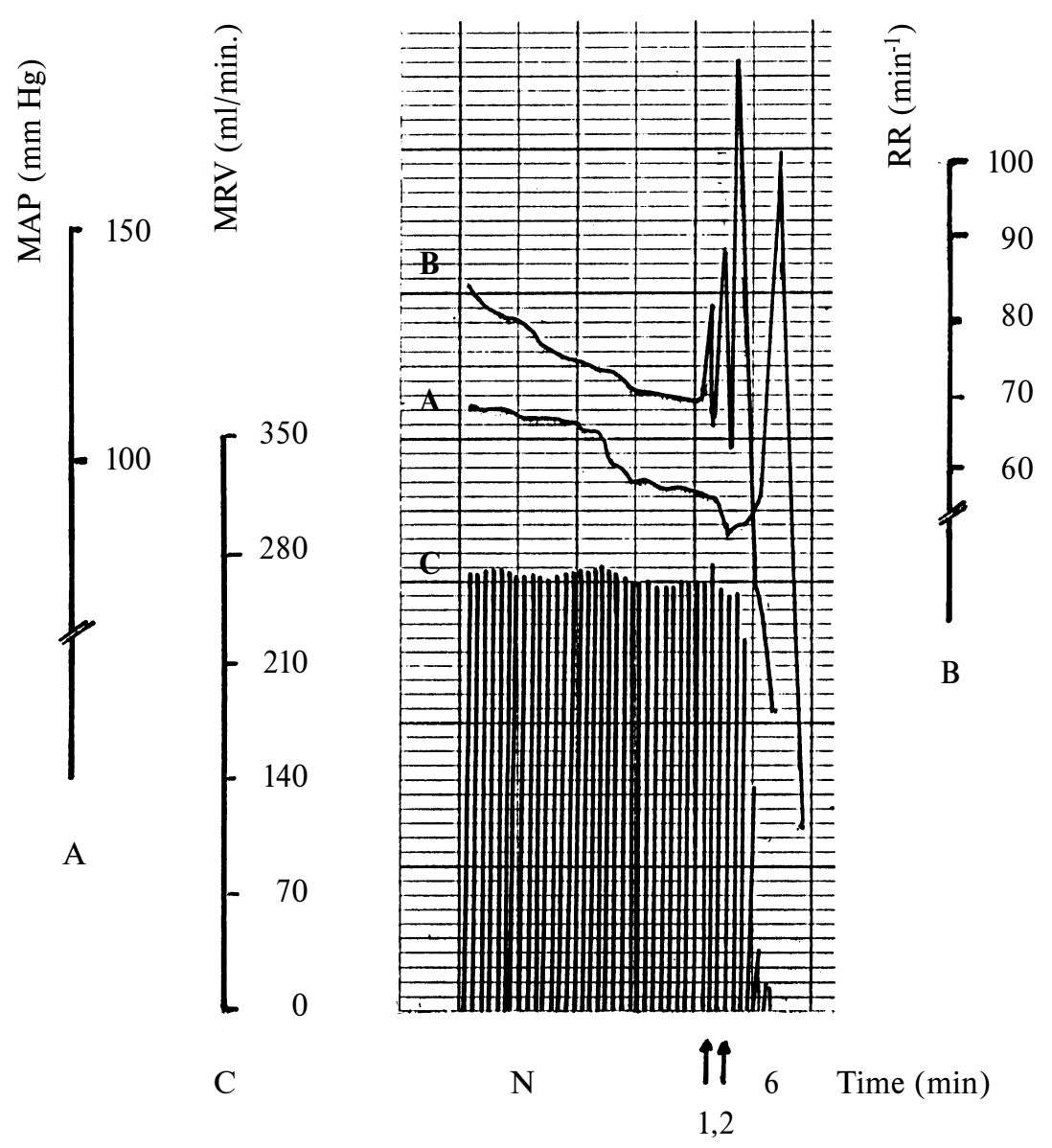

Fig. 1: Copy of graphical representation of actual values of the respiratory rates (RR, B), minute respiratory volumes (MRV, C), mean arterial pressures (MAP, A) and electrocardiograms (ECG) in a rat intoxicated with soman without treatment: (1) administration of soman; (2) administration of saline; (N) before the first administration (1). 
II

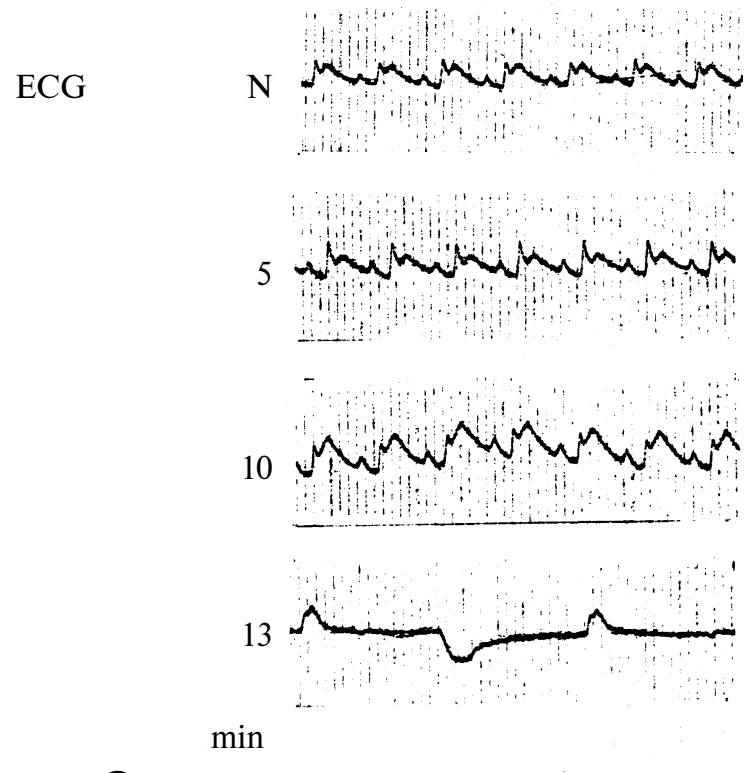

III
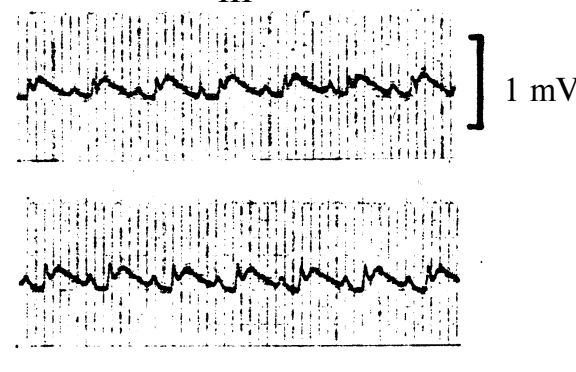

it

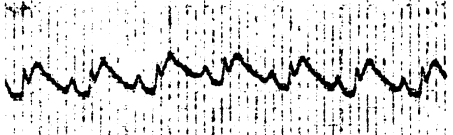

-

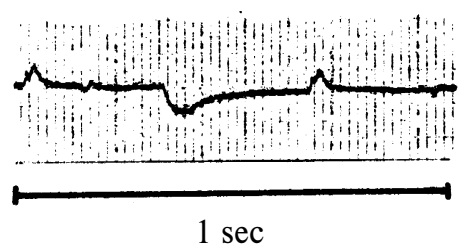

吉

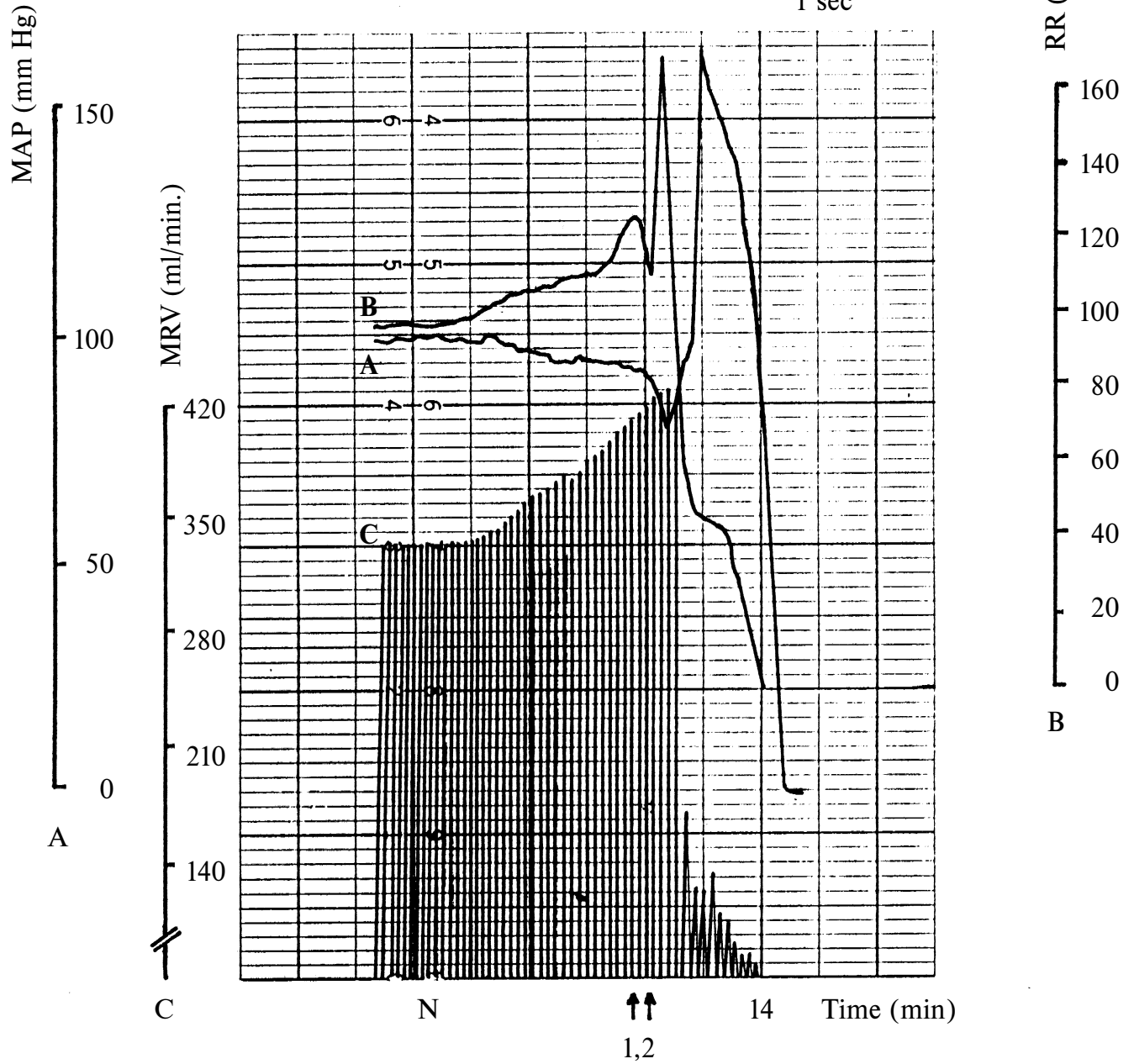

Fig. 2: Copy of graphical representation of actual values of the respiratory rates (RR, B), minute respiratory volumes (MRV, C), mean arterial pressures (MAP, A) and electrocardiograms (ECG) in a rat intoxicated with soman and treated with atropine: (1) administration of soman; (2) administration of atropine; (N) before the first administration (1). 

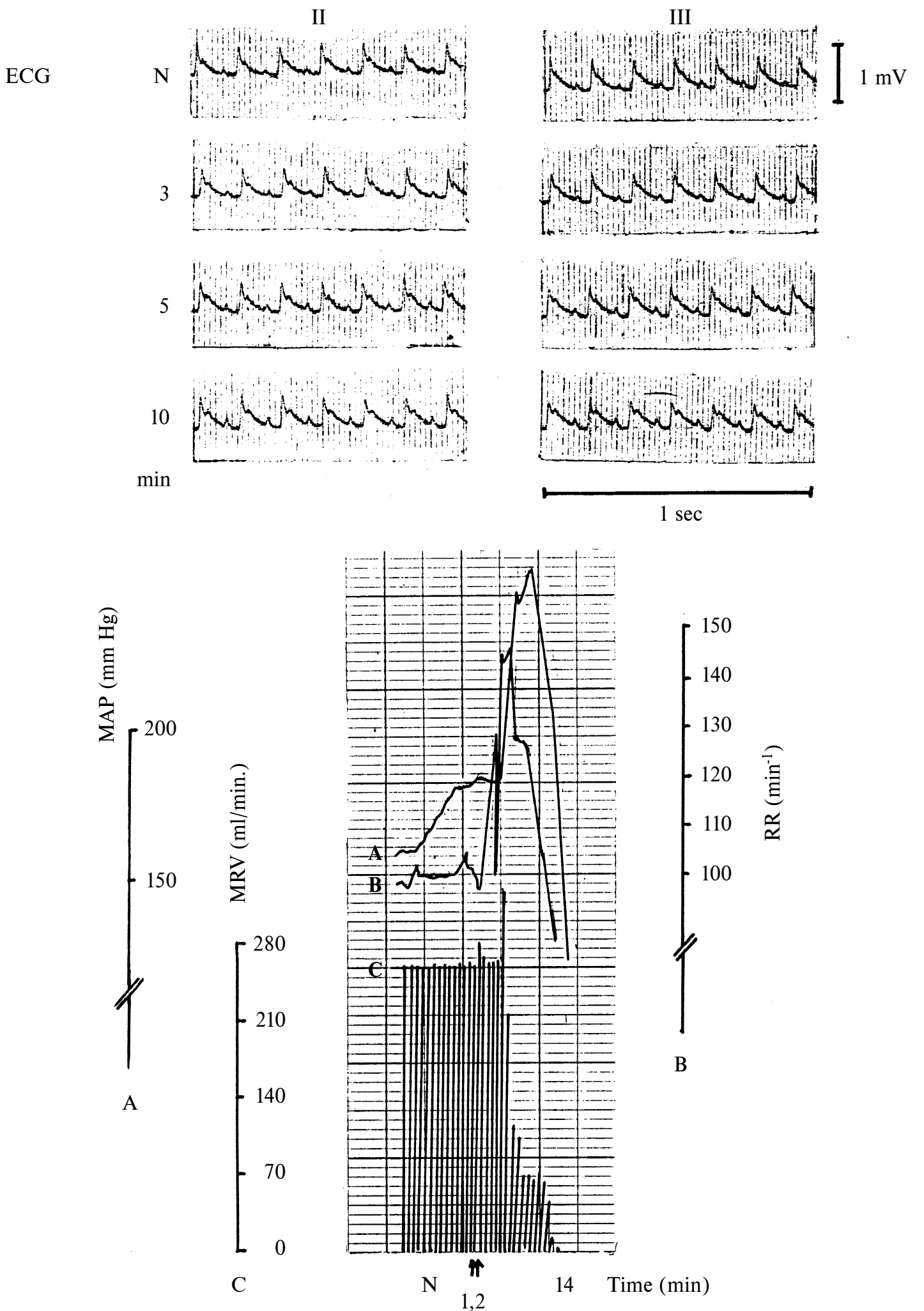

Fig. 3: Copy of graphical representation of actual values of the respiratory rates (RR, B), minute respiratory volumes (MRV, C), mean arterial pressures (MAP, A) and electrocardiograms (ECG) in a rat intoxicated with soman and treated with pralidoxime plus atropine: (1) administration of soman; (2) administration of pralidoxime plus atropine; (N) before the first administration (1). 
II

ECG

200

$-150$

A
$\mathrm{N}$

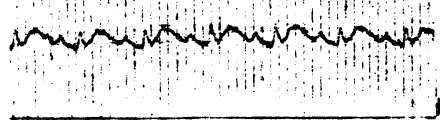

10

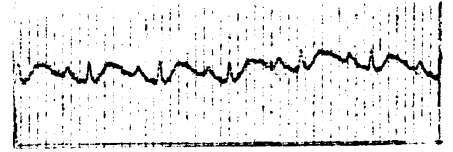

30

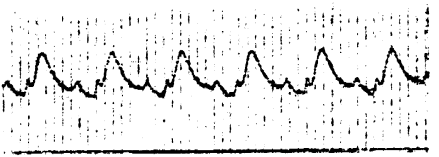

34

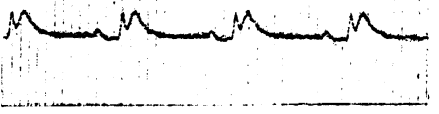

$\min$
III
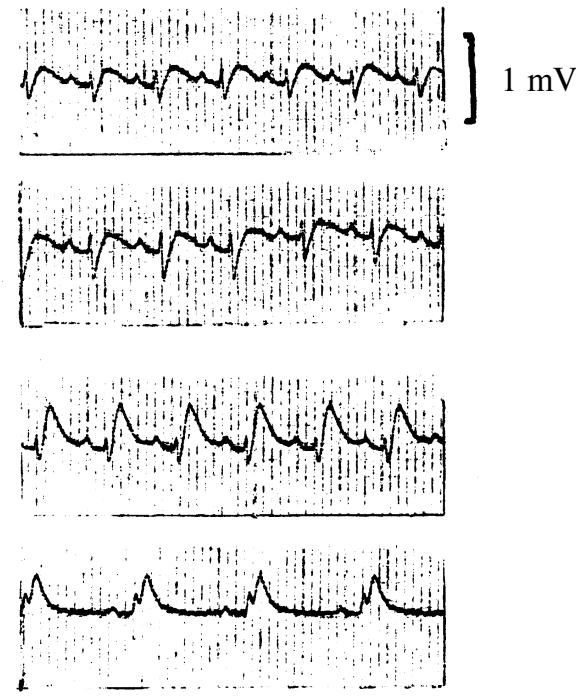

$1 \mathrm{sec}$
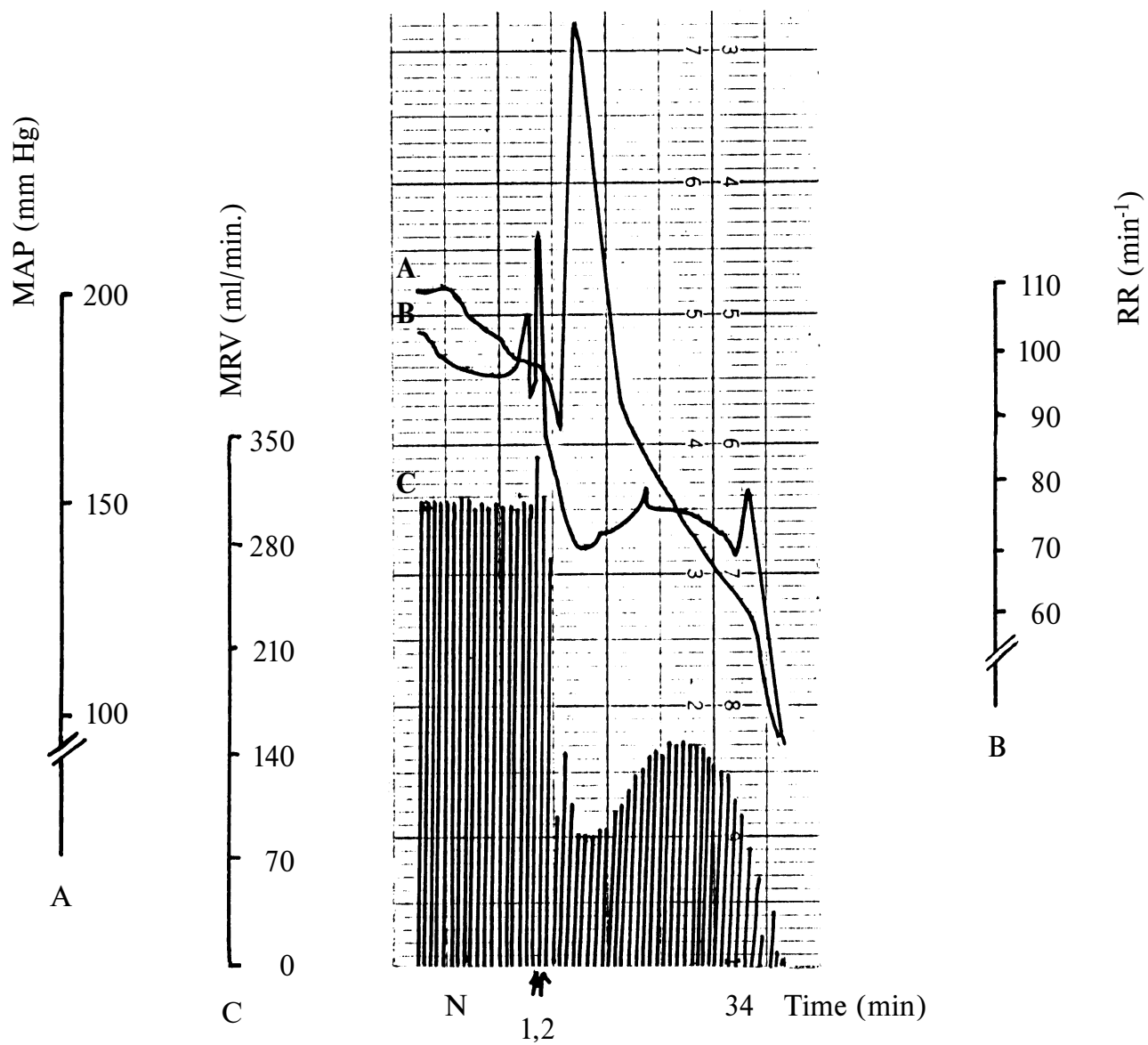

当

Fig. 4: Copy of graphical representation of actual values of the respiratory rates (RR, B), minute respiratory volumes (MRV, C), mean arterial pressures (MAP, A) and electrocardiograms (ECG) in a rat intoxicated with soman and treated with obidoxime plus atropine: (1) administration of soman; (2) administration of obidoxime plus atropine; (N) before the first administration (1). 
II

ECG

30

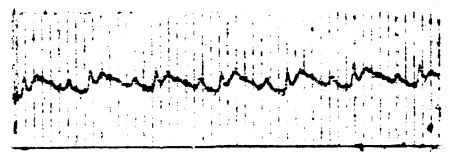

60

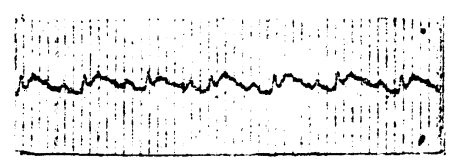

120

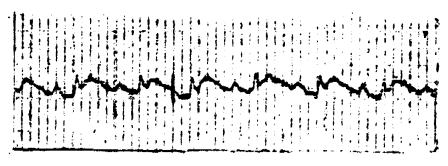

$\min$
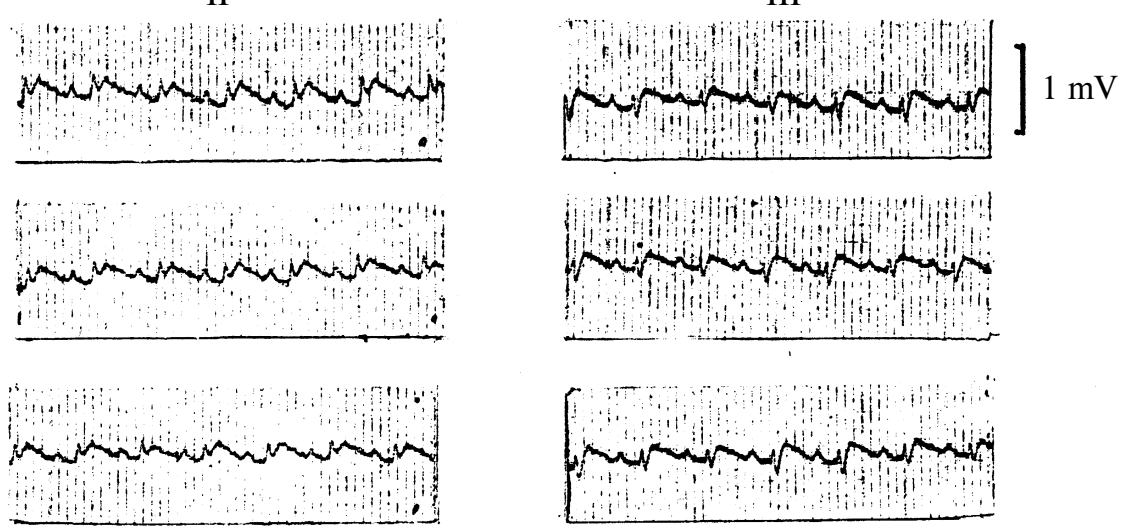

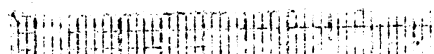
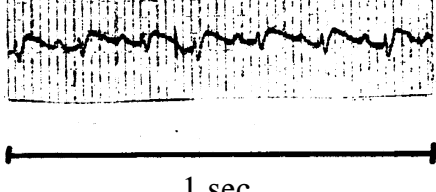

$1 \mathrm{sec}$

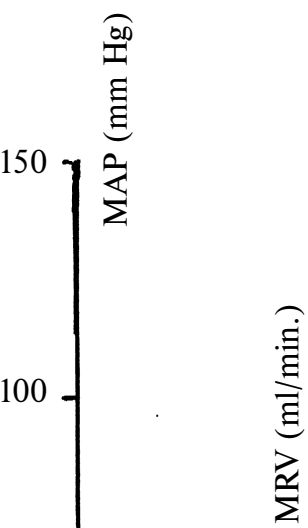

$50-$$$
350
$$

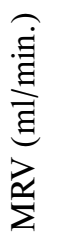

350
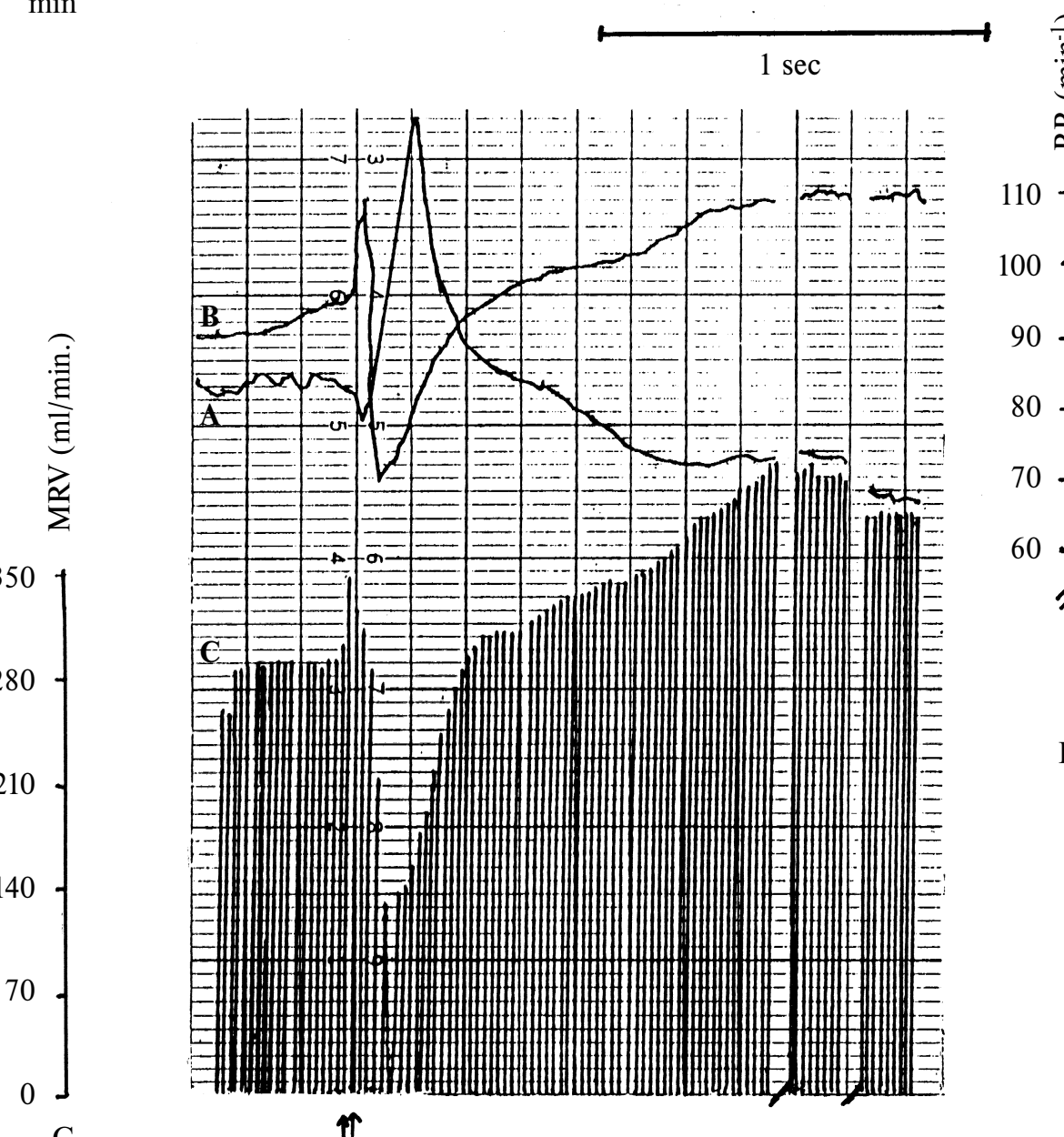

声

A
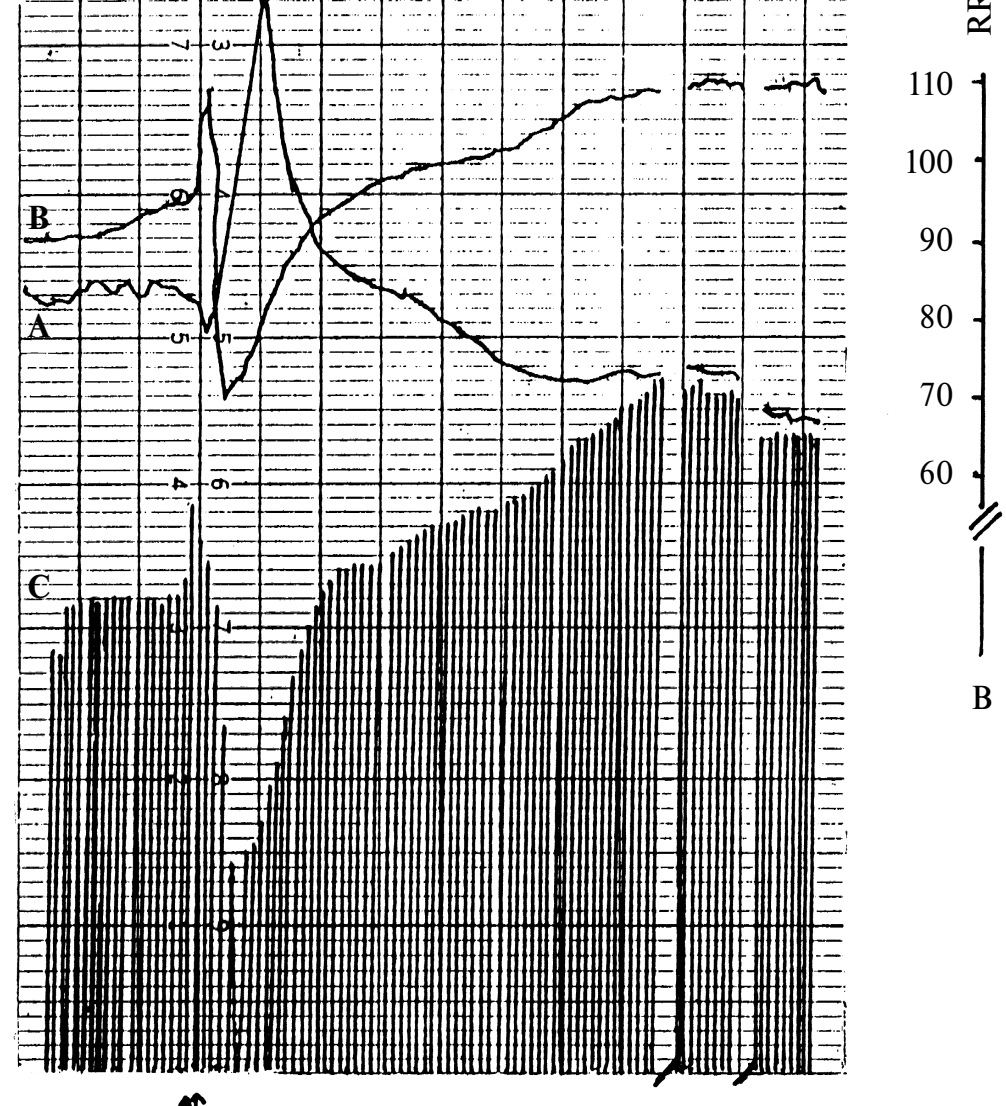

B

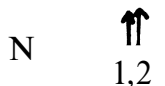

$60 \quad 90 \quad 120 \quad$ Time (min)

Fig. 5: Copy of graphical representation of actual values of the respiratory rates (RR, B), minute respiratory volumes (MRV, C), mean arterial pressures (MAP, A) and electrocardiograms (ECG) in a rat intoxicated with soman and treated with HI-6 plus atropine: (1) administration of soman; (2) administration of HI-6 plus atropine; (N) before the first administration (1). 
effects of HI-6 on mean arterial pressure and ECG last significantly longer compared to obidoxime or pralidoxime (Fig. 5). The rats died within $112 \mathrm{~min}$ on average and some of them survived till the end of experiments (120 minutes following soman challenge) (Tab. 1). The soman-induced respiratory depression as well as hypotension were practically abolished and no changes in ECG were observed in surviving rats (Fig. 5).

\section{Discussion}

The death of soman-poisoned experimental animals is usually caused by respiratory and subsequent circulatory paralysis which may be of central origin, because soman has been shown to be a potent central respiratory depressant $(3,17)$. Soman-induced respiratory depression can be mediated by a hindbrain cholinergic pathway due to high inhibition of brain AChE activity $(10,11,14)$. The disturbance of cardiac function includes changes in arterial pressure and heart rate, cardiac arrythmias and ECG abnormalities (21).

Different therapeutic effects were observed when various oximes in combination with atropine were used to treat soman-poisoned rats. While obidoxime as well as pralidoxime in combination with atropine seems to be almost ineffective in protecting rats poisoned with a supralethal dose of soman because they died within a few minutes following soman challenge, rats treated with the oxime HI-6 in combination with atropine survived for almost 2 hours.

Our results might not be explained solely by significant differences in the reactivating efficacy of the oximes studied $(10,12,24)$, but also by other antidotal mechanisms of the oxime HI-6, such as direct antimuscarinic action and restoration of neuromuscular transmission (27). In addition, the oxime HI- 6 is able to penetrate the blood-brain barrier in a concentration sufficient to produce some biochemical and physiological changes necessary for antagonizing soman-induced central toxic effects, although the quaternary structure of HI-6 limits this penetration and, therefore, the reactivating efficacy of HI-6 in the central nervous system is not as high as it is in the peripheral compartment $(5,10,16)$.

The oxime HI-6 in combination with atropine seems to be significantly more efficacious to prevent rats from soman-induced toxic signs compared to obidoxime or pralidoxime. On the other hand, the therapeutic efficacy of the oxime HI-6 in combination with atropine is not completely satisfactory, because only about $65 \%$ of soman-poisoned rats survived until the end of experiment (120 minutes following soman challenge). The therapeutic effectiveness of HI-6 in combination with atropine is limited by a relatively low central antimuscarinic effect of atropine and central reactivating efficacy of HI-6 (13). Atropine is able to cross the blood-brain barrier, but a relatively large dose is necessary to achieve central antimuscarinic effects owing to its lower lipophilicity and affinity to the central muscarinic receptors compared to other antimuscarinic drugs such as biperiden, benactyzine or scopolamine $(1,7)$. The reactivating effectiveness of HI-6 is higher in the peripheral nervous system compared to the central nervous system due to its rather difficult penetration through the blood-brain barrier $(6,11,20)$.

In conclusion, our data confirm that HI-6 is a significantly more efficacious oxime than currently available pralidoxime or obidoxime in the case of the antidotal treatment of severe soman poisoning. Nevertheless, its therapeutic efficacy is rather limited when it is combined with atropine probably because of the lack of central reactivation efficacy of HI-6 and central antimuscarinic effects of atropine.

\section{Acknowledgements}

The authors express their appreciation to Mrs E. Reslová for her skillful technical assistance and to Mr Bláha for his help with statistical evaluation.

\section{References}

1. Bajgar J, Patočka J, Herink J, Fusek J, Hrdina J. Effect of benactyzine, atropine and chlorpromazine on blood-brain barrier permeability in rats. Activ Nerv Sup 1978;20:56-62.

2. Bajgar J. Present view on toxidynamics of soman poisoning. Acta Med (Hradec Králové) 1996;39:101-5.

3. Chang EC, Foster RE, Beers ET, Rickett DL, Filbert MG. Neurophysiological concomitants of soman-induced respiratory depression in awake, behaving guinea pigs. Toxicol Appl Pharmacol 1990;102:233-8.

4. Clement JG. HI-6: reactivation of central and peripheral acetylcholinesterase following inhibition by soman, sarin and tabun in vivo in the rat. Biochem Pharmacol 1982;31:1283-7.

5. Clement JG. Central activity of acetylcholinesterase oxime reactivators. Toxicol Appl Pharmacol 1992;112:104-9.

6. Dawson RM. Review of oximes available for the treatment of nerve agent poisoning. J Appl Toxicol 1994;14:317-31.

7. Ellenwood EHJr, Nikaido AM, Gupta SK, Heatherly DG, Nishita JK Comparison of central nervous system and peripheral pharmacodynamics to atropine pharmacokinetics. J Pharmacol Exp Ther 1990;255:1133-41.

8. Fleisher JH, Harris JW. Dealkylation as a mechanism for aging of cholinesterase after poisoning with pinacolyl methylphosphonofluoridate. Biochem Pharmacol 1965; 14:641-9.

9. Kadar T, Raveh L, Cohen G et al. Distribution of ${ }^{3} \mathrm{H}$-soman in mice. Arch Toxicol 1985;58:45-9.

10. Kassa J. Comparison of efficacy of two oximes (HI-6 and obidoxime) in soman poisoning in rats. Toxicology 1995;101:167-74.

11. Kassa J, Bajgar J. Changes of acetylcholinesterase activity in various parts of brain following non-treated and treated soman poisoning in rats. Mol Chem Neuropathol 1998;33:175-84.

12. Kassa J, Cabal J. A comparison of the efficacy of a new asymmetric bispyridinium oxime BI- 6 with currently available oximes and $\mathrm{H}$ oximes against soman by in vitro and in vivo methods. Toxicology 1999;132:111-8.

13. Kassa, J, Fusek J. The influence of anticholinergic drug selection on the efficacy of antidotal treatment of soman-poisoned rats. Toxicology 2000;154:67-73.

14. Kok A. REM sleep pathway and anticholinesterase intoxication: a mechanism for nerve agent-induced central respiration failure. Med Hypotheses 1993;41:141-9.

15. Lallement G, Dorandeu F, Filliat P, Carpentier P, Baille V, Blanchet G. Medical management of organophosphate-induced seizures. J Physiol (Paris) 1998;92:369-73.

16. Lundy PM, Shih T-M. Examination of the role of central cholinergic mechanisms in the therapeutic effects of HI-6 in organophosphate poisoning. J Neurochem 1983;40:1321-7.

17. Marrs TC. Organophosphate poisoning. Pharmacol Ther 1993;58:51-66.

18. McDonough JR, Shih T-M. Neuropharmacological mechanisms of nerve agent induced seizure and neuropathology. Neurosci Biobehav Rev 1997;21:559-79.

19. Ohtomi S, Takase M, Kunagoi F. Sarin poisoning in Japan. A clinical experience in Japan Self Defense Force (JSDF) Central Hospital. Int Rev Arm Force Med Ser 1996;69:97-102.

20. Rousseaux CG, Dua AK. Pharmacology of HI-6, an H series oximes. Can J Physiol Pharmacol 1989;67:1183-9. 
21. Saadeh AM, Farsakh NA, Al-Ali MK. Cardiac manifestations of acute carbamate and organophosphate poisoning. Heart 1997;77:461-8.

22. Sachs, L.: Angewandte Statistik, $2^{\text {nd }}$ ed. Springer, Berlin, 1992:p. 207

23. Shih T-M, Whalley ChE, Valdes JJ. A comparison of cholinergic effects of HI-6 and pralidoxime-2-chloride (2-PAM) in soman poisoning. Toxicol Let 1991;55:131-47.

24. Shih T-M. Comparison of several oximes on reactivation of soman-inhibited blood, brain and tissue cholinesterase activity in rats. Arch Toxicol 1993;67:637-46.

25. Taylor P. Anticholinesterase agents. In: The Pharmacological Basis of Therapeutics, ${ }^{\text {th }}$ ed. Eds.: Hardman JG, Limbird LE. McGraw Hill, New York, USA, 1996: pp. 161-76.

26. Tryphonas L, Clement JG. Histomorphogenesis of soman-induced encephalocardiomyopathy in Sprangue-Dawley rats. Toxicol Pathol 1995; 23:393-7.

27. van Helden HPM, Busker RW, Melchers BPC, Brijunzeel PLB. Pharmacological effects of oximes: how relevant are they? Arch Toxicol 1996;70:779-86.

Submitted November 2001.

Accepted April 2002.

Doc. MUDr. Jiří Kassa, CSc., Purkyně Military Medical Academy, P.O. Box 35/T, 50001 Hradec Králové, Czech Republic. e-mail: kassa@pmfhk.cz 